\title{
Helminth Parasites of the Three Racerunner Lizards: Eremias pleskei Nikolsky, 1905 (Pleske's Racerunner-Transcaucasian Racerunner), Eremias strauchi Kessler, 1878 (Strauch's Racerunner) and Eremias suphani Basoglu \& Hellmich, 1968 (Suphan Racerunner) collected from Eastern Part of Turkey
}

\author{
S. DÜŞEN ${ }^{1 *}$, Y. KUMLUTAŞ ${ }^{2}$, Ç. ILGAZ ${ }^{2}$, H. YAKA ${ }^{1}$, F. KARADAYI $^{1}$
}

\begin{abstract}
${ }^{1}$ Pamukkale University, Faculty of Science and Arts, Department of Biology, Kinikli Campus, Kinikli, 20017 Denizli, Turkey, E-mail: sdusen@pau.edu.tr,serdar2290@yahoo.com; ${ }^{2}$ Dokuz Eylül University, Faculty of Science, Department of Biology, 35160, Buca, İzmir/Turkey
\end{abstract}

\begin{abstract}
Summary
In this investigation, a total of 44 racerunner lizard samples (Eremias pleskei, Eremias strauchi, and Eremias suphani) collected from eastern part of Turkey were examined for the first time for helminths. Eremias pleskei was harboured 1 species of acanthocepalan (in cystacanth stage), E. strauchi was harboured 2 species of nematodes, and E. suphani was harboured 3 species of nematodes and 1 species of cestode. E. strauchi represents a new host record for Spauligodon eremiasi, and Spauligodon saxicolae E. suphani represents a new host record for Spauligodon eremiasi, S. saxicolae, Physaloptera sp., and Oochoristica tuberculata, and also, E. pleskei represents a new host record for unidentified acanthocepalan (in cystacanth stage). Also, Turkey is a new locality record for Spauligodon eremiasi.
\end{abstract}

Keywords: Eremias pleskei; Eremias strauchi; Eremias suphani; Racerunner lizards; Helminth; Turkey

\section{Introduction}

The helminth parasites of three racerunner lizards: Eremias pleskei Nikolsky, 1905 (Pleske's Racerunner-Transcaucasian Racerunner), Eremias strauchi Kessler, 1878 (Strauch's Racerunner), and Eremias suphani Başoğlu \& Hellmich, 1968 (Suphan Racerunner) were examined in this study.

The genus Eremias Fitzinger, 1834 is inhabited mostly sand, arid steppe, and desert areas which are distributed from northern China, Mongolia, Korea, Central and southwest Asia to southeastern Europe (Rastegar-Pouyani \& Nilson, 1997). E. pleskei is more slender bodied than $E$. strauchi and E. suphani with the total length up to $15 \mathrm{~cm}$. It occurs in the left-bank valley of the river Aras in Armenia and in Nakhichevan (Nahcivan), Azerbaijan in the eastern Transcaucasia. It is also known from extreme east of Turkey and in the north-western Iran (Ananjeva et al., 2006; Baran et al., 2012). It prefers arid, sandy, partly rock areas with desert conditions. It is very active hides in small spots of sparse herbaceous vegetation on volcanic ground. The vertical distribution of the species varies from 500 and $1.700 \mathrm{~m}$. asl in Turkey (Baran et al., 2004; Baran et al., 2012). E. strauchi is larger and thicker bodied than E. pleskei with a total length up to $20 \mathrm{~cm}$ or longer. In North Eurasia the species is distributed in the eastern Transcaucasia: the valley of the middle current of Aras river, from the south-eastern foothills of the Karabakh range and the valley of Bargushat in the south-east up to the southern spurs of the mountain Aragaz and Oktemberyanskaya steppe in the west, in the Karabakh desert and on the plateau Zuvand, as well as in the south-western Turkmenistan (southern slopes of the mountain ranges Kyupendag, Karagez and Kopet Dagh). It occurs in eastern Turkey and the North-west and North-east of Iran, in Iranian Azerbaijan (Ananjeva et al., 2006; Baran et al., 2004; Baran et al., 2012). It inhabits desert-like, dry open places with pebbly substrates and little vegetation with a vertical distribution to $3500 \mathrm{~m}$.asl. E. suphani is medium sized lizard with a total length up to $20 \mathrm{~cm}$. It is known from Van, Bitlis, and Ağrı in the eastern Anatolia. It is found in desert-like, dry open places with pebbly substrates and little vegetation. It has been recorded up to $2400 \mathrm{~m}$ asl (Franzen \& Heckes, 1999; Baran et al., 2012).

So far, there has been no published study on helminths of the Turkish racerunner lizards in Turkey. We report for the first time helminths of three species from Turkey.

\section{Materials and methods}

The lizard samples were used in this study, obtained from Dokuz Eylül University, Faculty of Science, Department of Biology, Zoology Museum Collection in İzmir, Turkey. 
Racerunner lizards were collected by hand between 2000 and 2002, from four different localities in eastern part of Turkey: E. suphani (1) (Güzelsu district between Başkale (Van) 10th km, $2159 \mathrm{~m}$. asl, 38 $15^{\circ} 29.65^{\prime \prime} \mathrm{N} ; 43^{\circ} 52^{\prime}$ $32.84^{\prime \prime} \mathrm{E}$ ); E. strauchi (2) Aralık (Iğdır province) between Nakhichevan 5th km, $812 \mathrm{~m}$. asl, $39^{\circ} 50^{\prime} 24.56^{\prime \prime} \mathrm{N} ; 44^{\circ} 32^{\prime}$ $05.80^{\prime \prime}$ E); E. pleskei and E. strauchi (3) (Aralı between Nakhichevan (Nahçivan), Gödekli Village $30 \mathrm{~km}$ to Nakhichevan, $812 \mathrm{~m}$ asl, $39^{\circ} 49^{\prime} 16.25^{\prime \prime} \mathrm{N} ; 44^{\circ} 35^{\prime} 38.07^{\prime \prime}$ E), and E. strauchi (4) (Aralık-Nakhichevan, between

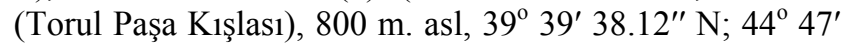
48.35" E) (Fig. 1).

In total, 10 E. pleskei (6 males, 4 females), 14 E. strauchi (10 males, 4 females), and 20 E. suphani (14 males, 6 females) samples were examined for helminth parasites. The mean \pm SD snout-vent length (SVL) of specimens were E. pleskei $45.45 \pm 8.17 \mathrm{~mm}$, with a range from 36.34 to $55.84 \mathrm{~mm}$, E. strauchi $56.44 \pm 7.19 \mathrm{~mm}$, with a range from 46.08 to $70.72 \mathrm{~mm}$, and E. suphani $63.89 \pm 5.16 \mathrm{~mm}$, with a range from 45.14 to $70.08 \mathrm{~mm}$, respectively.

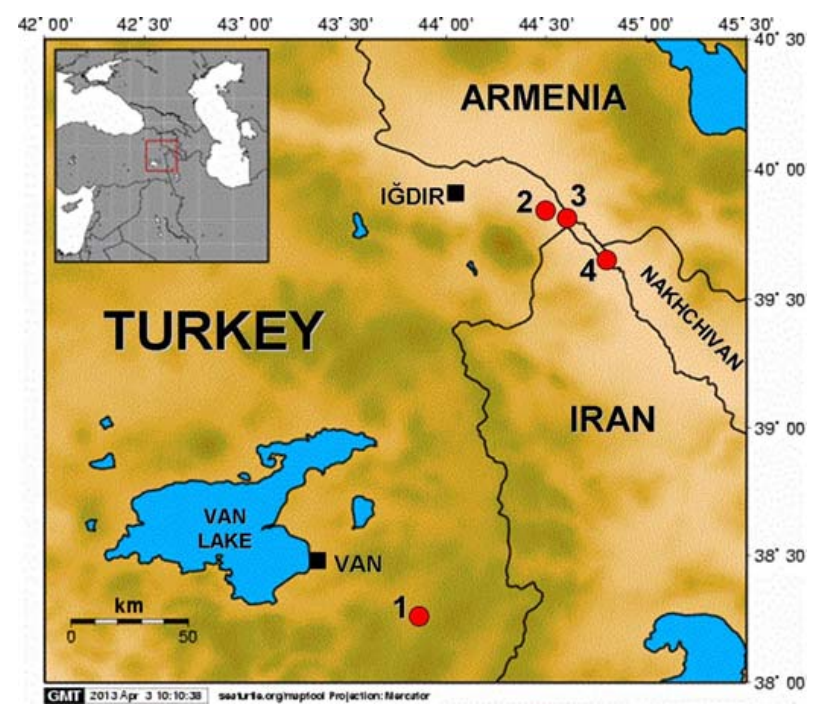

Fig. 1. The collection locations of Eremias pleskei, E. strauchi, and E. suphani from the eastern part of Turkey

(For location numbers see the Material and methods section)

Body cavities of lizard samples were opened by a longitudinal ventral incision. The alimentary canal were excised and separated into stomach, small intestine, large intestine and rectum. The contents of each part and other organs were poured into petri dishes for examination under a stereomicroscope. Cestode, nematode and acanthocephalan samples were stained with acetocarmine, dehydrated, cleared in cedar oil or xylol; nematodes were cleared in glycerol and samples were mounted in Canada Balsame or Entellan ${ }^{\circledR}$. Intensities are presented as mean values $( \pm \mathrm{SD})$ followed by the range. Voucher host specimens were deposited in Dokuz Eylül University, Faculty of Science Department of Biology, Zoology Museum, and parasite specimens were deposited in Pamukkale University, Faculty of Sciences and Arts, Department of Biology, Denizli, Turkey (PAU-HELM-1-5/2013).

\section{Results and discussion}

In summary, eleven individuals of one acanthocephalan species (unidentified cystacanths) were collected $10 \mathrm{E}$. pleskei samples examined. Helminths were observed the embedded small intestine mucosa of this species, 4 (40\%) individuals of E. pleskei were harboured only one helminth; the remaining $6(60 \%)$ were uninfected. There were $2.75 \pm 1.50$ helminth individuals per infected host.

Fourteen E. strauchi examined, individuals of 2 helminth species were collected. Helminths were recorded the small intestine, large intestine and rectum of this species. No individual host was harboured more than 2 helminth species. Of the infected lizards, 4 (50\%) were harboured 2 species of helminth, $4(50 \%)$ were harboured 1 species of helminth. There were $9.12 \pm 8.46$ helminth individuals per infected host.

Twenty E. suphani examined, 310 individuals of 4 helminth species were collected. Helminths were recorded the stomach, small intestine, large intestine, rectum of this species. No individual host was harboured more than 3 helminth species. Of the infected lizards, 3 (15\%) were harboured 3 species of helminth, 9 (45\%) were harboured 2 species of helminth, $6(30 \%)$ was harboured 1 species of helminth. There were $1.83 \pm 0.70$ helminth species per infected host and 17.22 \pm 10.53 helminth individuals per infected host. No helminths were observed in lungs and body cavities of these examined three Eremias species. Data on helminth infections of E. pleskei, E. strauchi, and E. suphani are recorded in Table 1.

The genus, Spauligodon includes a cosmopolitan group of nematode parasites of reptiles according to Bursey and Goldberg (2011) comprising at least 47 described species, with 20 of them occurring in the Palearctic region (Jorge et al., 2012). Ikromov and Cho (2004) reported S. saxicolae from Eremias velox in Uzbekistan; Uhlírová (2005) reported S. saxicolae from Darevskia caucasica in Zakatali province, Azerbaijan. Murvanidze et al. (2008) reported $S$. saxicolae in Lacerta strigata, L. saxicola, L. rudis and Coluber jugularis in Georgia; Carretero et al. (2011) observed S. saxicolae from Podarcis vaucheri Complex in Algeria. In Turkey Yıldırımhan (1999) reported S. saxicolae from L. danfordi, L. saxicola, L. siculus, and Podarcis muralis (Northwestern part of Turkey).

Uhlírová (2005) reported S. eremiasi from Eremias velox caucasica in Baku province, Azerbaijan; Murvanidze et al. (2008) reported S. eremiasi from E. velox in Georgia; Bakiyev and Kirillov (2007) reported $S$. eremiasi from a viperid snake, Vipera ursinii in Volga Basin, Russia.

The genus Oochoristica contains medium sized of tapeworm species parasitic as adults in reptiles and mammals (Hughes et al., 1941; Yamaguthi, 1959). Hughes et al. (1941) published detailed report for O. tuberculata from different reptile species (Acanthodactylus pardalis, Agama agama, A. sanguinolenta, Chalcides ocellatus, Eumeces schneiderii, L. agilis, L. lepida, L. muralis, L. ocellata, L. viridis, Ophisaurus apodus, Uromastix acanthinurus, 
Table 1. Helminths of Eremias pleskei, E. strauchi and E. suphani from Turkey

\begin{tabular}{|c|c|c|c|c|c|c|}
\hline HELMINTH (Helm. Coll. No.) & Host & $\begin{array}{c}\text { Developmental } \\
\text { Stage }\end{array}$ & $\begin{array}{c}\text { Site of } \\
\text { Infection }\end{array}$ & $\begin{array}{c}\text { No. of } \\
\text { InfectedHost } \\
(\%) \\
\end{array}$ & $\begin{array}{c}\text { Mean } \\
\text { Intensity } \\
( \pm \text { SD }) \\
\end{array}$ & Range \\
\hline \multirow{2}{*}{$\begin{array}{l}\text { PHARYNGODONIDAE } \\
\text { Spauligodon eremiasi } \\
\text { Markov et Bogdanov, } 1961 \\
\text { (PAU-HELM-1/2013) }\end{array}$} & E. strauchi & Adult & SI, LI, R & $5(35.71)$ & $11( \pm 7.21)$ & $3-21$ \\
\hline & E. suphani & Adult & SI, LI, R & $5(25)$ & $4.6( \pm 6.42)$ & $1-16$ \\
\hline \multirow{2}{*}{$\begin{array}{l}\text { Spauligodon saxicolae } \\
\text { Sharpilo, 1961 } \\
\text { (PAU-HELM-2/2013) }\end{array}$} & E. strauchi & Adult & SI, LI, R & $7(50)$ & $2.57( \pm 1.27)$ & $1-4$ \\
\hline & E. suphani & Adult & SI, LI, R & $6(30)$ & $8.17( \pm 8.42)$ & $1-22$ \\
\hline $\begin{array}{l}\text { SPIRURIDAE } \\
\text { Physaloptera } \text { sp. } \\
\text { (PAU-HELM-3/2013) }\end{array}$ & E. suphani & Adult & $\mathrm{S}$ & $18(90)$ & $12.3( \pm 9.75)$ & $1-32$ \\
\hline $\begin{array}{l}\text { LINSTOWIIDAE } \\
\text { Oochoristica tuberculata } \\
\text { (Rudolphi, 1819) Lühe, } 1898 \\
\text { (PAU-HELM-4/2013) }\end{array}$ & E. suphani & Adult & LI & $4(20)$ & $4( \pm 2.45)$ & $2-7$ \\
\hline $\begin{array}{l}\text { ACANTHOCEPHALA } \\
\text { Unidentified cystacanths } \\
\text { (PAU-HELM-5/2013) }\end{array}$ & E. pleskei & Larval & SI & $4(40)$ & $2.75( \pm 1.50)$ & $1-4$ \\
\hline
\end{tabular}

S: Stomach, SI: Small intestine; LI: Large intestine, R: Rectum

Varanus griseus, Cerastes vipera, Eryx jaculus, and Psammophis sibilans) in Spain and Africa, also Yamaguthi, (1959) reported this cestode from Mabuya, Coelopeltis (synonim of Malpolon) in Europe and Africa. So, there are several reptile host reports for $O$. tuberculata from different countries: Sharpilo et al. (2001) recorded O. tuberculata from L. agilis in Ukrain and Bulgaria; Ibrahim et al. (2005) reported $O$. tuberculata from Chalcides ocellatus in Libya; Bakiyev and Kirillov (2007) observed O. tuberculata from $V$. berus in Volga Basin, Russia; Murvanidze et al. (2008) recorded $O$. tuberculata from $A$. caucasica, and L. strigata in Georgia; Dugarov et al. (2012) recorded $O$. tuberculata from E. argus in Zabaikalie province, Russia. Yildirimhan (1999) reported O. tuberculata from $L$. viridis; Yıldırımhan et al. (2006) observed O. tuberculata from Laudakia caucasica in Dogubayazıt (Ağr1 Province), Turkey; Yıldırımhan et al. (2011) observed O. tuberculata from L. trilineata in Turkey (northwestern part). In this study, we observed $O$. tuberculata in E. suphani.

The genus Physaloptera members are parasitic nematodes in digestive tract, generally the stomach of mammals, birds, reptiles, and rarely amphibians. (Irwin-smith, 1921; Ortlepp, 1922; Yamaguthi, 1961). Ortlepp (1922) and Yamaguthi (1961) reported Physalopterid species from some reptile hosts (amphisbaenid, agamid, lacertid, varanid, chamaeleonid, elapid and viperids) from Europe (Spain, Italy), Asia (Turkestan), Africa (Algeria, Belgian Congo Morocco), South America (Brazil), USA and South Australia. Bakiyev and Kirillov (2007) reported a larval Physalopterid species ( $P$. clausa) from Natrix natrix, $V$. ursinii from $V$. berus in Volga Basin, Russia; Schad et al. (1960) published an annotated list about some Turkish 110 vertebrates. They recorded Physaloptera sp. from $L$. viridis in Turkey. Also, Cirak et al. (2010) reported the Physalopterid species, $(P$. clausa) it was the highest prevalence which observed in necroscopied hedgehog's (Erinaceus concolor) stomachs in Turkey. We observed Physaloptera sp. in the stomachs of E. suphani samples. E. strauchi, represents new host records for $S$. eremiasi, S. saxicolae; $E$. suphani represents new host records for $S$. eremiasi, $S$. saxicolae, Physaloptera sp., and O. tuberculata), and also E. pleskei represents new host record for unidentified acanthocepalan (in cystacanth stage) in Turkey.

In conclusion, this study has expanded the geographical and host range distribution of various helminth species. Future studies should also expand the host-parasite list of Turkish reptile helminthofauna.

\section{Acknowledgments}

We thank to Michaela Bařinová-Uhlířová (Tomas Bata University in Zlin, Czech Republic) who shared her valuable data to us, and Department of National Parks and Wildlife of the Ministry of Environment and Forestry of the Republic of Turkey, for their helps and permission.

\section{References}

Ananjeva, N. B., Orlov, N., Khalikov, R. G., DAREVSKY, I. S., RYABOV, S. A., BARABANOV, A. (2006): The Reptiles of Northern Eurasia: Taxonomic Diversity, Distribution, Conservation Status (1st edition), Pensoft Publishers; Bulgaria, 245 pp.

BakiYeV, A. G., Kirillov, A. A. (2007): Main results of 
the study of parasites snakes Volga Basin (Part 1, Protozoa and Helminths). Sci. J. Mag. Mold. Univ., 4, 60 - 68 (In Russian)

BARAn, İ., Kumlutaş, Y., ToK, C. V., Ilgaz, Ç., KaskA, Y., Olgun, K., TÜrkozan, O., İRet, F. (2004): On two herpetological collections made in east Anatolia (Turkey). Herpetozoa, 16 (3/4): 99 - 114.

Baran, İ., Ilgaz, Ç., Avci, A., Kumlutaş, Y., Olgun, K. (2013): Türkiye Amfibi ve Sürüngenleri (Turkish Amphibians and Reptiles). TÜBİTAK Popüler Bilim Kitapları, TÜBİTAK, Ankara. 204 pp. (In Turkish)

Bursey, C. R., And GoldBerg, S. R. (2011): A new species of Spauligodon (Nematoda: Oxyuroidea: Pharyngodonidae) in Latastia longicaudata (Sauria: Lacertidae) from Kenya. J. Parasitol., 97: 460 - 462. DOI: 10.1645/GE-2645.1

Carretero, M. A., Roca, V., Larbes, S., Ferrero, A., JORGE, F. (2011): Intestinal helminth parasites of wall lizards, Podarcis vaucheri complex (Sauria: Lacertidae) from Algeria. J. Herpetol., 45 (3): 385 - 388. DOI: 10.1670/10-118.1

Cirak, V. Y., Senlik, B., Aydogdu, A., Selver, M., AKYOL, V. (2010): Helminth parasites found in hedgehogs (Erinaceus concolor) from Turkey. Prev. Vet. Med., 97: 64 - 66. . DOI: 10.1016/j.prevetmed.2010.07.007.

Dugarov, Zh. N., Baldanova, D. R., Khamnueva, T. R. (2012): Parasite of the Lizard Eremias argus Peters, 1869 in Zabaikalie. Parazitologiya, 46 (6): 463 - 471 (In Russian with English abstract)

FRANZEN, M., HECKES, U. (1999): Eremias suphani Basoglu \& Hellmich, 1968 und Eremias strauchi Kessler, 1878 in der östlichen Türkei: Diagnostische Merkmale, Verbreitung und Lebensräume (Sauria: Lacertidae). Salamandra, 35 (4): 255 - 266

Hughes, R. C., BAKer, J. R., DAwson, C. B. (1941): The Tapeworms of Reptiles, Part I. Am. Mid. Nat., 25 (2): 454 - 468. ISSN: 00030031

Ibrahim, H. M. S., FADIEL, M. M., NAIR, G. A. (2005): Gastrointestinal Helminths of The Lizard Chalcides ocellatus from Benghazi, Libya. J. Helminthol., 79, 35 - 39. DOI: $10.1079 / \mathrm{JOH} 2004258$

Jorge, F., Carretero, M. A., Perera, A. Harris, D. J., RocA, V. (2012): A new species of Spauligodon (Nematoda: Oxyurida: Pharyngodonidae) in geckos from Sâo Nicolau Island (Cape Verde) and its phylogenetic assessment. J Parasitol., 98 (1): 160 - 166. DOI: 10.1645/GE2856.1

IKrOMOV, E. K., CHO, M. R. (2004): On new representatives of the helminth fauna of reptiles (Testudines and
Sauria) in Uzbekistan. J. Asia-Pacific. Entomol., 7: 13 17. DOI: 10.1016/S1226-8615(08)60196-X

IRWIN-SMITH, V. (1921): Notes on nematodes of the genus Physaloptera, with special reference to those parasitic in reptiles, (Part I). Proc. Linn. Soc. N. S. W., 46: $492-502$. Murvanidze, L., Lomidze, T. S., NikOlaishvili, K., JANKARASHVILI, E. (2008): The annotated list of reptile helminths of Georgia. Proc. Inst. Zool. Tbilisi, 23, $54-61$ ORTLEPP, R. J. (1922): The nematode genus Physaloptera Rudolphi, 1819. P. Zool. Soc. Lon., 1922: 999 - 1107. DOI: 10.1111/j.1469-7998.1922.tb07095.x

RAstegar-Pouyani, N., Nilson, N. (1997): A new species of Eremias (Sauria: Lacertidae) from Fars Province, South-Central Iran. Russ. J. Herpetol., 4 (2): 94 - 101. ISSN: 1026-2296

SchaD, G. A., Kuntz, R. E., Wells, W. H. (1960): Nematode parasites from Turkish vertebrates: An annotated list. Can. J. Zool., 38: 949 - 963. DOI: 10.1139/z60-101

Sharpilo, V. P., Biserkov, V., Kostadinova, A., BeHNKE, J. M., KuZMIN, Y. I. (2001): Helminths of the sand lizard, Lacerta agilis (Reptilia, Lacertidae), in the Palaearctic: faunal diversity and spatial patterns of variation in the composition and structureof component communities. Parasitology, 123 (04): 389 - 400. DOI: 10.1017/S0031182001008587

UHLířovÁ, M. (2005): Comparative study on the fauna of parasitic oxyuroids (Nematoda: Octuroidea) of reptiles from Azerbaijan and selected areas of the Near East. Helminthologia, 42 (3): 171 - 186

YamaguTi, S. (1959): Systema Helminthum: The Cestodes of Vertebrates. Vol. II. Intersciences Publishers, London, England 860 pp.

YAMAGUTI, S. (1961): Systema Helminthum: The nematodes of vertebrates. Vol. III., Part II. Nematodes of Amphibians. Intersciences Publishers Ltd. London, England 679 pp.

YILDIRIMHAN, H. S. (1999): Helminth fauna of lizards species belonging to Lacertidae (Reptilia) family distributed in Bursa and its around ( $\mathrm{PhD}$ thesis). Uludağ University, Institute of Science. 120 pp, Bursa (In Turkish, with English abstract)

Yildirimhan, H. S., Goldberg, S. R., Bursey, C. R (2006): Helminth parasites of the Caucasian agama, Laudakia caucasia, and the roughtail rock agama, Laudakia stellio (Squamata: Agamidae), from Turkey. Comp. Parasitol., 2 (73): 257 - 262. DOI: 10.1654/4205.1

Yildirimhan, H. S., Bursey, C. R., Altunel, F. N. (2011): Helminth parasites of the Balkan green lizard, Lacerta trilineata Bedriaga 1886, from Bursa, Turkey. Turk. J. Zool., 35(4): 519 - 535. DOI: 10.3906/zoo-0910-1 